\title{
Calibration of the C-DAX Rapid Pasturemeter and the rising plate meter for kikuyu-based Northland dairy pastures
}

\author{
G.M. RENNIE ${ }^{1}$, W.MCG. KING ${ }^{1}$, M.R. PUHA ${ }^{1}$, D.E. DALLEY ${ }^{2}$, R.A. DYNES ${ }^{3}$ and M.P. UPSDELL ${ }^{1}$ \\ ${ }^{1}$ AgResearch, Ruakura Research Centre, PB 3123, Hamilton \\ ${ }^{2}$ DairyNZ, PO Box 160, Lincoln University, Christchurch \\ ${ }^{3}$ AgResearch, Lincoln Research Centre, PB 4749, Christchurch \\ grant.rennie@agresearch.co.nz
}

\begin{abstract}
Accurate estimation of pasture mass is essential for managing farm systems for top performance. The C-DAX Rapid Pasturemeter has the potential to provide fast, accurate estimates of pasture mass. However, the Pasturemeter has been calibrated for 'typical' temperate dairy pastures and its suitability for use on kikuyu (Pennisetum clandestinium)-based pastures in Northland, is unknown. This study determined the accuracy of the technology for estimation of pasture mass on kikuyu/ryegrass-based dairy pasture on the Northland Agricultural Research Farm at Dargaville, New Zealand. Monthly pasturemeter and rising plate meter (RPM) measurements were made over a year and compared with quadrat cut data. Large seasonal variations in the pasturemeter calibration at Dargaville reflected changes in pasture composition, although no specific kikuyu influence could be determined. Both the pasturemeter and the RPM benefit from the use of different seasonal calibration equations, specific to the region. The pasturemeter and RPM show similar accuracies for biomass (dry matter yield) estimation in Northland.
\end{abstract}

Keywords: pasture mass estimation, kikuyu, Northland, dairy, calibration

\section{Introduction}

A fast and accurate method of pasture mass estimation has long been seen as valuable for the agricultural industry (Earle \& McGowan 1979). However, pasture mass estimation technologies are used on only around $20 \%$ of New Zealand dairy farms (Clark et al. 2006). The low acceptance is due to perceived inaccuracies and the time and effort required for their regular use (Lile et al. 2001). The rising plate meter (RPM) is, perhaps, the most widely used pasture mass estimation technology although there are other methods, such as calibrated visual estimations or pasture capacitance probes, with similar accuracy (L'Huillier \& Thomson 1988).

The C-DAX Rapid Pasturemeter (Lawrence et al. 2007, www.pasturemeter.co.nz) is a tow-behind attachment for a quad bike that determines average pasture height as the sward breaks the light path of a light emitting and sensing photodiode array at $20 \mathrm{~mm}$ spacing. The pasturemeter can take numerous pasture cover readings (200 per second) across a paddock and can be used at speeds up to $20 \mathrm{~km} / \mathrm{h}$. Pasture mass is calculated from sward height with manufacturersupplied or user-defined equations.

The pasturemeter could reduce the time required to obtain paddock level estimates of pasture mass and has low inter-operator variation due to minimal operator input. Other mass estimation methods can show large variation between operators due to technique or subjectivity. Minimal operator training is necessary to ensure a representative paddock sampling. However, the manufacturer-supplied pasturemeter calibration equations have been developed using ryegrass/white clover (Lolium perenne/Trifolium repens) pastures at a limited number of localities.

The warm temperate Northland climate has allowed the widespread establishment of kikuyu (Pennisetum clandestinium), a $\mathrm{C}_{4}$ grass. In typical Northland dairy pastures, the relative importance of kikuyu and ryegrass changes markedly throughout the year. Kikuyu competes strongly with more desirable ryegrass during summer/ autumn but is inhibited in winter. Strong ryegrass growth and cooler temperatures in spring restricts kikuyu spread. High stolon density in established kikuyu increases the pasture density near the sward base. While stolons contribute little to grazeable mass, they can have a highly variable effect on pasture mass estimation technologies (Fulkerson \& Slack 1993).

The aim of this study was to assess the accuracy of the C-DAX Rapid Pasturemeter and the rising plate meter (RPM) in Northland dairy pastures using manufacturersupplied calibrations and then to develop calibrations specifically for those pastures.

\section{Methods}

Ryegrass/white clover pastures with varying contents of kikuyu at the Northland Agricultural Research Farm (NARF) at Dargaville were sampled 10 times between December 2007 and November 2008. Different paddocks were used each month. Two recently grazed paddocks of low pasture cover (2000 kg DM/ha ), two 
Table 1 Manufacturer supplied calibration equations for the C-DAX Rapid Pasturemeter and the Rising Plate Meter.

\begin{tabular}{lcccc}
\hline & \multicolumn{2}{c}{ Pasturemeter } & \multicolumn{2}{c}{ RPM } \\
\hline Month & Multiplier & Constant & Multiplier & Constant \\
Winter & 18.6 & 1117 & 140 & 500 \\
October & 15.3 & 1358 & 115 & 850 \\
November & 16.0 & 1530 & 120 & 1000 \\
December & 18.6 & 1818 & 140 & 1200 \\
January & 21.9 & 1978 & 165 & 1250 \\
February & 24.6 & 2017 & 185 & 1200 \\
March & 22.6 & 1850 & 170 & 1100 \\
\hline
\end{tabular}

of intermediate pasture cover (2000-3000 kg DM/ha) and two paddocks of high pasture cover (pre-grazing $3000 \mathrm{~kg} \mathrm{DM} / \mathrm{ha}$, depending on farm pasture cover) were chosen. The pastures were similar in botanical composition, differing only in length of time since grazing. In each paddock, eight $100 \times 32 \mathrm{~cm}$ quadrats were subjectively placed so as to cover a range in pasture heights. For each quadrat the following was conducted in order:

Pasturemeter measurement of pasture height, with the quadrat placed over the measured area after measurement.

RPM measurement of the pasture height (three measurements per quadrat).

Visual estimation of the pasture composition on the basis of total dry mater: \% legume, $\%$ broadleaved species, $\%$ grass, $\%$ dead material and $\%$ bare ground by comparison with Pasture Quality Calibration Sheets (developed by Meat NZ). The two major grass and legume species were noted.

The quadrat was then cut to ground level. The pasture sample was washed to remove soil contamination before drying at $80^{\circ} \mathrm{C}$ for a minimum of $24 \mathrm{~h}$ and recording the dry weight.

In addition, a strip of pasture adjacent to the long axis of each quadrat (viz. $8 \times 100 \mathrm{~cm}$ ) was cut as close as possible to ground level $(<1 \mathrm{~cm})$ without collecting any soil and was bulked for each paddock to give a 'paddock average' sample for dissection into grass leaf, grass stem, kikuyu leaf, kikuyu stem, legume, weeds and dead material. These samples were dried at $80^{\circ} \mathrm{C}$ for a minimum of $24 \mathrm{~h}$ before weighing and determination of botanical composition.

The Northland trial was part of a larger trial critically evaluating pasturemeter and RPM performance in dairy pastures throughout New Zealand.

\section{Statistical methods}

Pasture biomass (dry matter yield) estimations were predicted over the year using the mixed model
Figure 1 Pasture botanical composition (bulked sample from six paddocks collected monthly and dissected into kikuyu, total grass=grass leaf and stem, dead matter, legume and weeds) at the Northland Agricultural Research Farm from December 2007 to November 2008.

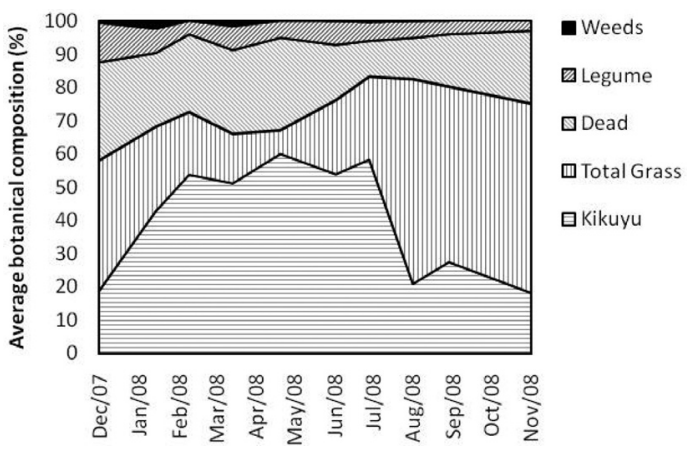

smoothers of Upsdell (1994). The daily varying calibration equations were calculated within the model from the smoothed data.

\section{Results}

\section{Pasture composition}

NARF pastures were ryegrass-dominant from August to December with increasing kikuyu content over the remainder of the year. Ryegrass, kikuyu and Роа апnиа were present in 94,74 and $23 \%$ of all quadrat samples, respectively. The high frequency of kikuyu was supported by the bulked paddock composition samples: kikuyu was found in every paddock, contributing 3 to $75 \%$ of the total sample dry weight. Total grass leaf and stem, excluding kikuyu, represented 0 to $75 \%$ of the total dry weight of the botanical composition samples (Fig. 1).

\section{Estimation of pasture mass - pasturemeter}

Standard calibration equations

Pasture mass was estimated using the seasonal calibrations supplied with the pasturemeter (Table 1). These were compared with the pasture mass determined by quadrat cutting to ground level and drying. Over the measurement period, the mean error (deviation from quadrat cut biomass) was $504 \mathrm{~kg} \mathrm{DM} / \mathrm{ha}$ and errors ranged from -620 to $1460 \mathrm{~kg} \mathrm{DM} / \mathrm{ha}$ (Fig. 2).

\section{Northland re-calibration}

The pasturemeter output (pasture height) versus the actual mass of the pasture was used to determine daily calibration factors for the $y=\mathrm{m} x+\mathrm{c}$ type calibration equation. The variation of the pasturemeter calibration constant throughout the year was small, within the standard error of a single constant. A single constant of $880 \mathrm{~kg} \mathrm{DM} / \mathrm{ha}$ was therefore used for simplicity (Fig. 3). This constant was lower than the manufacturer supplied values of 1117 
Figure 2 Errors in pasture mass prediction (estimated DM - actual DM) throughout the year using Pasturemeter (-), RPM with monthly calibrations (-..), RPM1 with a single calibration equation (---) and a combined graph of all three in Northland dairy pasture. The bands for Pasturemeter, RPM and RPM1 graphs are the 95\% confidence intervals. The bands on the combined graph are the $95 \%$ LSD intervals for differences between means. The curves are significantly different where the bands do not overlap.

\section{Current Northland Equations}

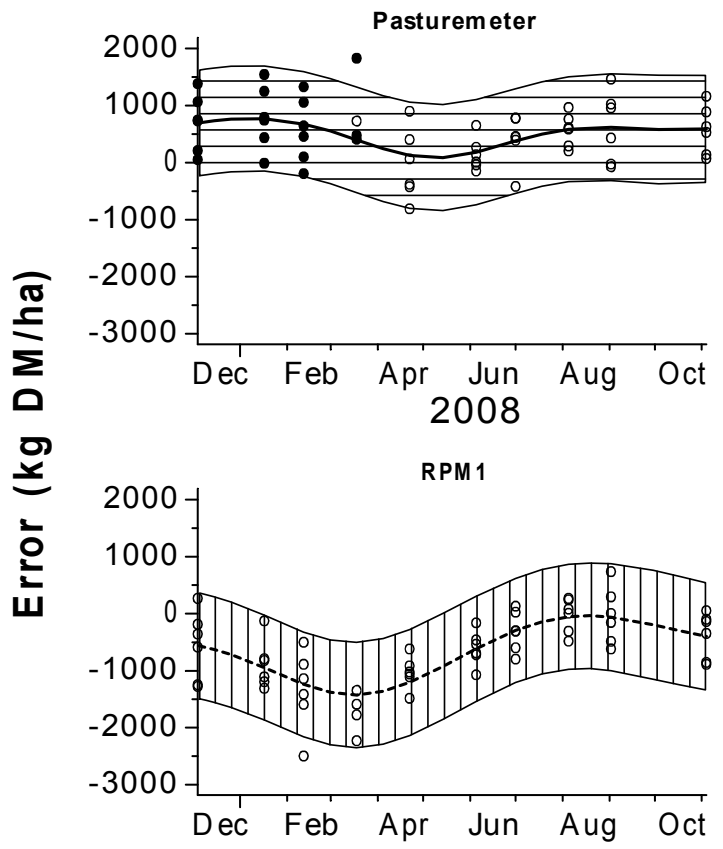

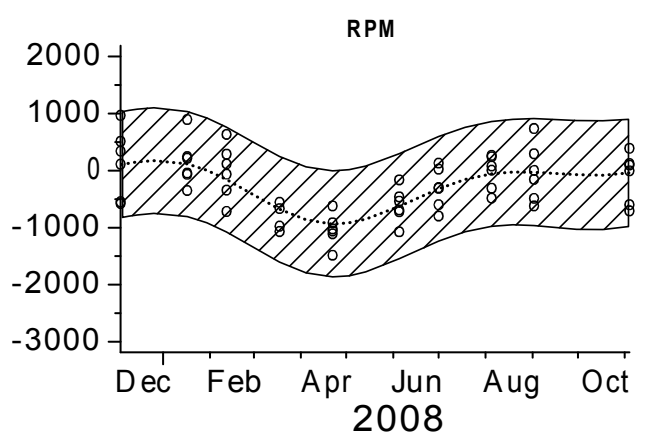

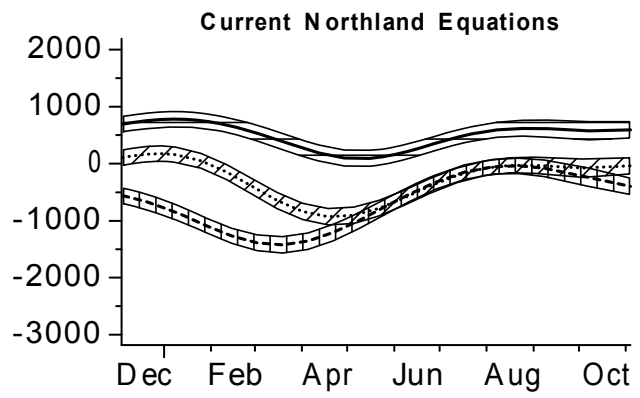

Figure 3 New C-DAX Rapid Pasturemeter calibration equations for Northland with and without a single yearly constant. Mean \pm $95 \%$ confidence interval shown.

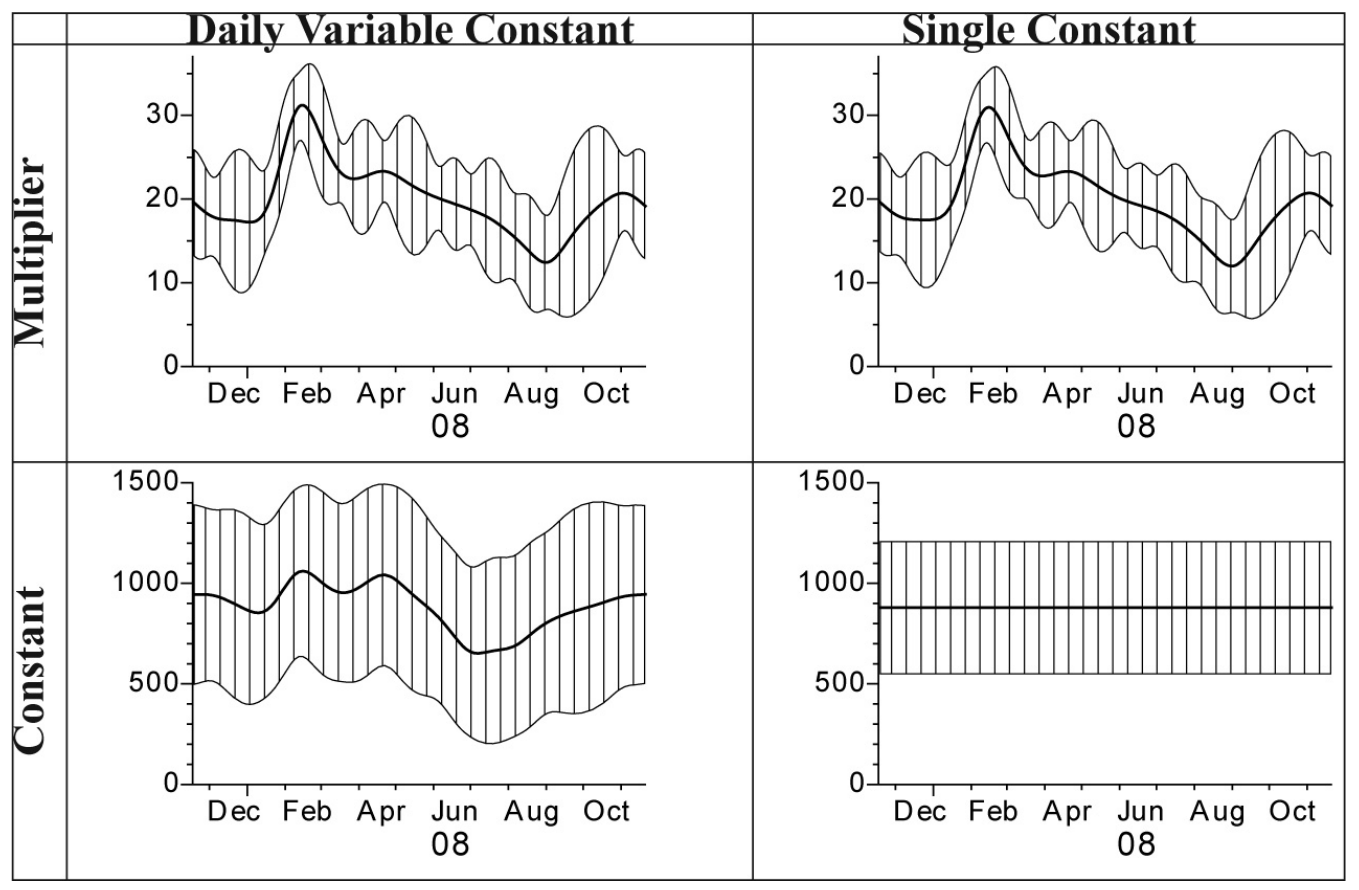


Figure 4 Errors in pasture mass prediction (estimated DM - actual DM) throughout the year using original Pasturemeter calibration (-), Northland specific calibrations (- - ), Northland specific calibration with a kikuyu covariate (---), and a combined graph of all three in Northland dairy pasture. The bands on the Current, Northland and Kikuyu graphs are the $95 \%$ confidence intervals. The bands on the combined graph are the $95 \%$ LSD intervals for differences between means. The curves are significantly different where the bands do not overlap.

\section{Pasturemeter Equations}
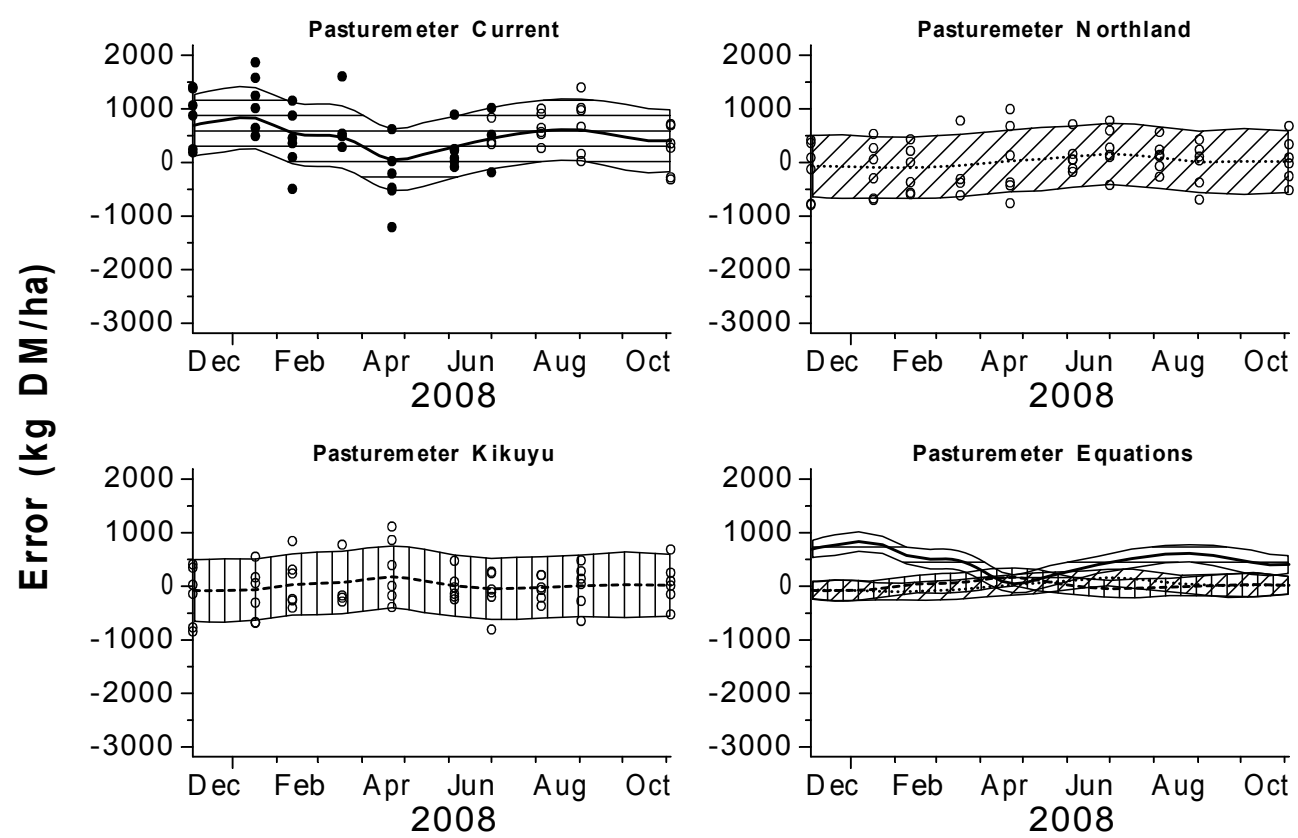

Figure 5 New rising plate meter calibration equations for Northland with and without a single yearly constant. Mean $\pm 95 \%$ confidence interval shown.

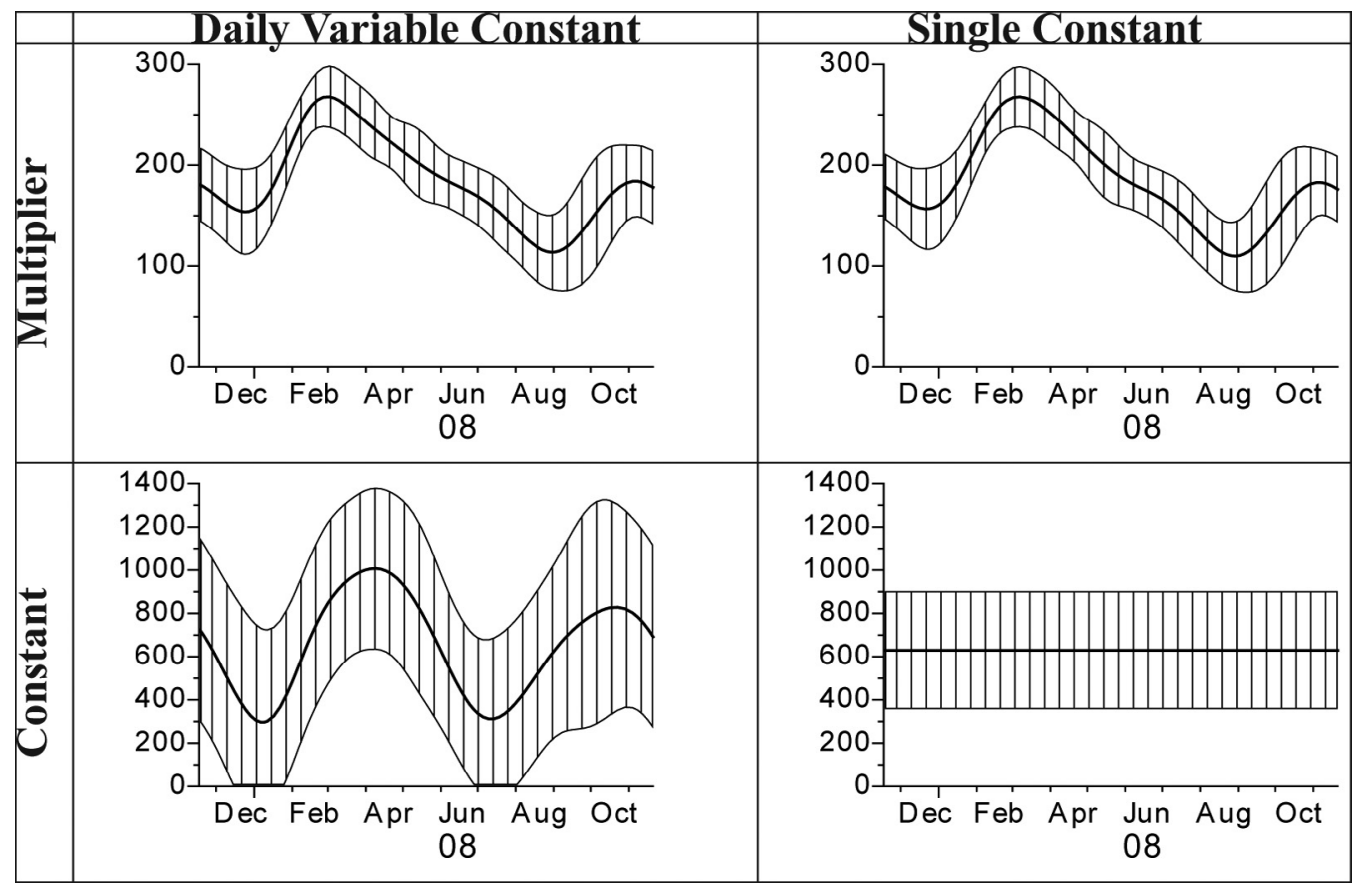


to $2017 \mathrm{~kg} \mathrm{DM} / \mathrm{ha}$.

The calibration equation multiplier range showed greater variation than the manufacturer supplied multipliers (Table 1) and can vary daily (Fig. 3). From these data, a multiplier can be estimated for a more Northland specific pasturemeter calibration.

The pasturemeter was also recalibrated to take into account the varying kikuyu content throughout the year. However, the inclusion of kikuyu $\%$ as a covariate did not improve the precision of the analyses (Fig. 4).

\section{Estimation of pasture mass - rising plate meter Current industry equations}

Pasture mass was estimated using the RPM with both the seasonally calibrated (RPM) equations (Table 1) and a single (RPM1) yearly equation (winter seasonal equation). Pasture mass estimations were compared with the pasture mass as determined from quadrat cutting and drying. The RPM measurements with seasonal calibrations had a mean error of $-254 \mathrm{~kg} \mathrm{DM} /$ ha with errors ranging from -1620 to $810 \mathrm{~kg} \mathrm{DM} / \mathrm{ha}$. The RPM1 pasture mass estimation using a single equation gave an average error of $-662 \mathrm{~kg} \mathrm{DM} / \mathrm{ha}$ and monthly errors ranging from -1720 to $180 \mathrm{~kg} \mathrm{DM} / \mathrm{ha}$.

\section{Northland re-calibration}

Determination of the daily calibration equations for the RPM was simplified by using a single constant. The variation in the constant was predominantly within the standard error of the single constant (Fig. 5). The constant of 630 was generally lower than the commonly used monthly equations for the RPM. The multiplier range for the Northland specific RPM calibrations was greater than for the commonly used RPM equations.

The RPM was re-calibrated to take into account the varying pasture kikuyu content throughout the year. Again, there was no improvement in the precision of the analyses (Fig. 6).

\section{Discussion}

Both the C-DAX Rapid Pasturemeter and the RPM showed large pasture mass prediction errors on Northland kikuyu pastures, when using manufacturer or industry recommended seasonal calibrations (Table 2). During summer, the pasturemeter can overestimate pasture mass by more than $1000 \mathrm{~kg} \mathrm{DM} /$ ha. The RPM can underestimate by a similar amount in autumn. The root mean square error was similar for the two methods, 900 and 828 for the pasturemeter and RPM, respectively. These deviations reflect both the variation and the bias within the predictions and show comparability between the two methods. Some use of the RPM without changing from the default winter calibrations has been reported (Litherland et al.
2008). In Northland, a large underestimation of pasture mass will result from using a sub-optimal constant. However, the ranking of pasture mass may still allow a useful comparison between paddocks to be made. Many pasture-based strategic decisions, such as winter nitrogen use or feed budgeting, are made over winter and spring. The pasturemeter and the RPM both predict pasture mass more accurately during this period than at other times of the year.

Pasture height measurement has previously been shown to be no more precise than other indirect pasture estimation technologies, such as the plate and probe, on Northland dairy pastures (Piggot 1986). Some of the inherent disadvantages of using sward height to estimate pasture mass also apply to the pasturemeter. Over-estimation of herbage mass with increasing sward height is common due to a high proportion of the mass being concentrated in the lower layers (Frame 1993). However, unlike other techniques based on pasture height, such as the sward stick, it is not possible to distinguish stem or seed head height from the more important free standing leaf height (Webby \& Pengelly 1986; Litherland et al. 2008).

The RPM can estimate herbage mass of sample plots with similar reliability to properly calibrated visual assessments. On a whole-farm scale, however, the RPM may underestimate herbage mass which is assumed to be due to a difference in RPM application or operation (Thomson et al. 2001). The pasturemeter is likely to show similar or better accuracy in the estimation of pasture biomass compared with the RPM over the whole farm. Pasturemeter operator input is minimal and therefore low operator error and inter-operator variation is expected. Sampling a representative area and driving speed are the only operator influences, which is an improvement on other techniques. In this study no consideration was given to paddock-scale pasture mass determination.

Systematic errors in the pasture mass estimations using industry-supplied calibration equations (large deviation between estimated and actual dry matter) indicate the need for Northland specific calibration equations for both the pasturemeter and the RPM. The calibrations developed here have the potential to provide more accurate pasture mass estimates than the industry supplied standards.

It was expected that a kikuyu response would be detected due to dry matter accumulation in stoloniferous material. Calibration for this would increase the constant value for the calibration equations. The low constant determined here is contrary to this expectation. Previous accounts of RPM use on kikuyu swards have shown unacceptably low accuracy for total dry matter estimation. The accuracy of previous work was 
Table 2 Prediction errors for the C-DAX Rapid Pasturemeter and RPM using: manufacturer or industry specified equations, Northland specific equations or Northland specific equations with a kikuyu covariate.

\begin{tabular}{lccccccc}
\hline & \multicolumn{2}{c}{ Manufacturer/industry equations } & \multicolumn{2}{c}{ Northland specific equations } & \multicolumn{3}{c}{ Northland with kikuyu covariate } \\
& Pasture meter & RPM & RPM1 & Pasture meter & RPM & Pasture meter & RPM \\
\hline rms error $^{1}$ & 900 & 828 & 1075 & 515 & 454 & 437 & 351 \\
Mean error & 504 & -254 & -662 & -2 & -6 & 5 & 3 \\
Stdev error & & 743 & 787 & 843 & 515 & 454 & 437 \\
\hline
\end{tabular}

${ }^{1}$ Root mean squared error

${ }^{2}$ Standard deviation error

Figure 6 Errors in pasture mass prediction (estimated DM - actual DM) throughout the year using original monthly rising plate meter calibration (-), Northland specific calibrations (-....), Northland specific calibration with a kikuyu covariate (----), and a combined graph of all three in Northland dairy pasture. The bands on the Current, Northland and Kikuyu graphs are the $95 \%$ confidence intervals. The bands on the combined graph are the 95\% LSD intervals for differences between means. The curves are significantly different where the bands do not overlap.

\section{RPM Equations}
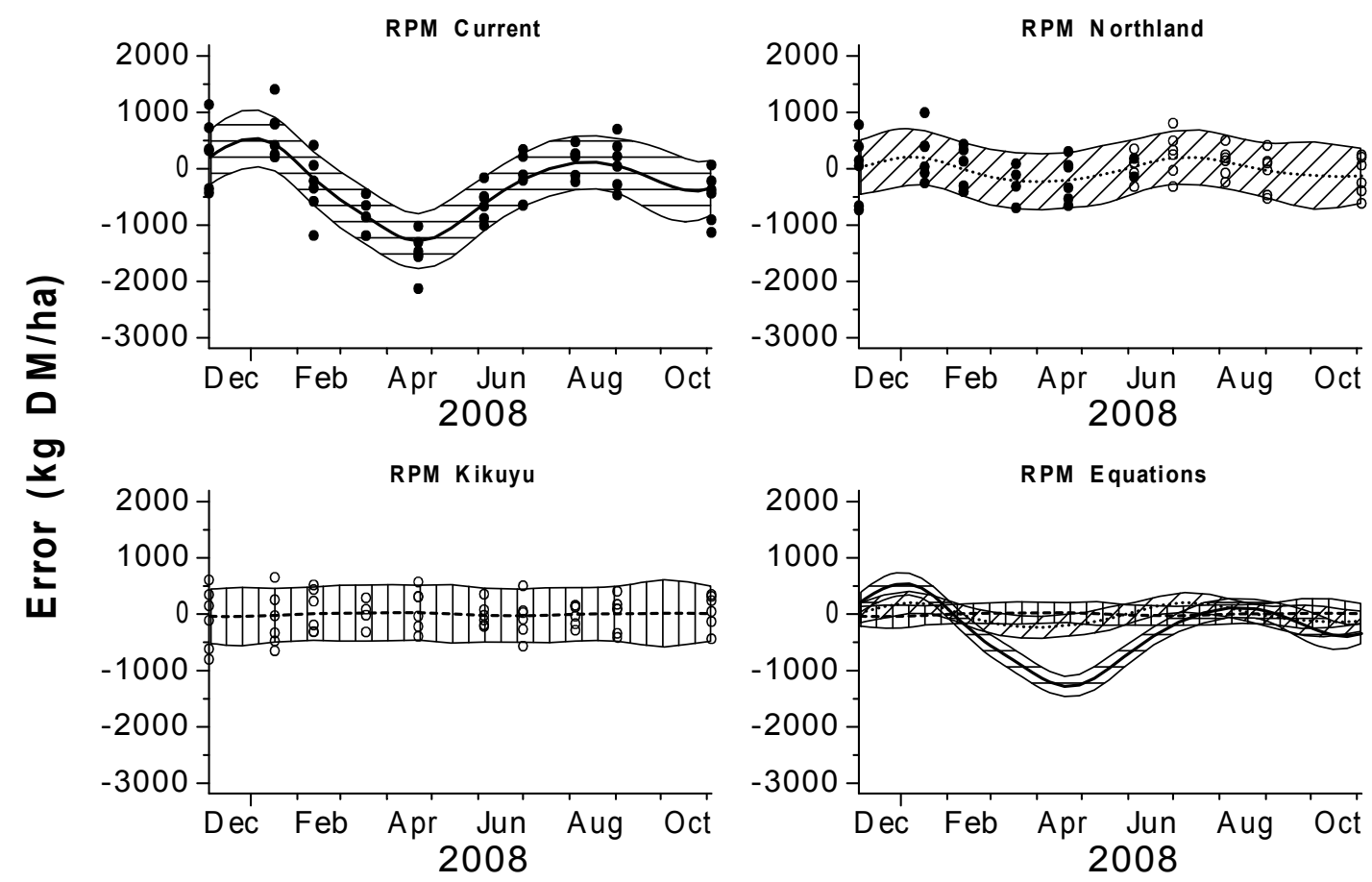

increased using grazeable or green dry matter estimates (Fulkerson \& Slack 1993; Piggot 1988).

The choice of pasture estimation method will largely be influenced by cost, convenience and personal preference (L'Huillier \& Thomson 1988). The cost of the C-DAX Rapid Pasturemeter is considerably greater than the RPM. The pasturemeter has potential drawbacks such as wheel or skid marks on wet pasture and loss of sward familiarity. However, reduced labour cost, ease of use and convenience of the pasturemeter could greatly increase the frequency of use compared with the RPM.

The trial was run for one year on one farm in Northland, therefore, further validation of these equations on unrelated Northland dairy properties is required before recommendations on their widespread use can be made.

\section{Conclusion}

Large errors occur when estimating the pasture 
mass of Northland dairy pastures if commonly used calibration equations are applied to data from the C-DAX Rapid Pasturemeter and the rising plate meter. During December and January the Pasturemeter may overestimate pastures by more than $1000 \mathrm{~kg} \mathrm{DM} / \mathrm{ha}$ while the RPM may underestimate by similar amounts during March and April. The new calibration equations reported here should be a better choice when using either of these technologies for pasture mass estimation on Northland dairy pastures whether they contain kikuyu or not. Further validation is required to ensure the robustness of the new calibration equations.

\section{ACKNOWLEDGEMENTS}

The authors would like to thank Northland Agricultural Research Farm staff and Chris and Kate Boom for their assistance with the Dargaville field trials.

\section{REFERENCES}

Clark, D.A.; Litherland, A.J.; Mata G.; BurlingClaridge, R. 2006. Pastures monitoring from space. Proceedings of the S I D E Conference 7:108-123.

Earle, D.F.; McGowan, A.A. 1979. Evaluation and calibration of an automated rising plate meter for estimating dry matter yield of pasture. Australian Journal of Experimental Agriculture and Animal Husbandry 19: 337-343.

Frame, J. 1993. Herbage mass. pp. 39-67. In: Sward measurement handbook, $2^{\text {nd }}$ edition. Eds. Davies, A.; Baker, R.D.; Grant, S.A.; Laidlaw, A.S. The British Grasslands Society. Reading, England.

Fulkerson, W.J.; Slack, K. 1993. Estimating mass of temperate and tropical pastures in the subtropics. Australian Journal of Experimental Agriculture 33: 865-869.

Lawrence, H.; Yule, I.; Murray, R. 2007. Pasture Monitoring Technologies. Proceedings of the SIDE Conference 8:126-131
L'Huillier, P.J.; Thomson, N.A. 1988. Estimation of herbage mass in ryegrass/white clover dairy pastures. Proceedings of the New Zealand Grassland Association 49: 117-122.

Lile, J.A.; Blackwell, M.B.; Thomson, N.A.; Penno, J.W.; Macdonald, K.A.; Nicholas, P.K.; Lancaster, J.A.S.; Coulter, M. 2001. Practical use of the rising plate meter (RPM) on New Zealand dairy farms. Proceedings of the New Zealand Grassland Association 63: 159-164.

Litherland, A.J.; Webby, R.; Fraser, T.J.; Matthew, C.; McCleod, K.; Walcroft, J.; Bryant, J.; Devantier, B.; Hoogendoorn, C.J.; Moss, R.; Clarke-Hill, W.J.; Schreurs, P.J. 2008. Indirect measurement of pasture mass and pasture growth on sheep and beef pastures. Proceedings of the New Zealand Grassland Association 70: 137-144.

Thomson, N.A.; Upsdell, M.P.; Hooper, R.; Henderson, H.V.; Blackwell, M.B.; McCallum, D.A.; Hainsworth, R.J.; MacDonald, K.A.; Wildermoth, D.D.; BishopHurley, G.J.; Penno, J.W. 2001. Development and evaluation of a standardised means for estimating herbage mass of dairy pastures using the rising plate meter. Proceedings of the New Zealand Grassland Association 63: 149-157.

Piggot, G.J. 1986. Methods for estimating pasture dry matter on dairy farms in Northland. Proceedings of the New Zealand Grassland Association 47: 243-247.

Upsdell, M.P. 1994. Bayesian smoothers as an extension of non-linear regression. The New Zealand Statistician 29: 66-81.

Webby, R.W.; Pengelly, W.J. 1986. The use of pasture height as a predictor of feed level in north island hill country. Proceedings of the New Zealand Grassland Association 47: 249-253. 